\title{
Apical hypertrophic cardiomyopathy: diagnosis, medical and surgical treatment
}

\author{
Jerzy Paluszkiewicz ${ }^{1}$, Beata Krasinska², Hendrik Milting ${ }^{3}$, Jan Gummert ${ }^{4}$, Małgorzata Pyda ${ }^{1}$ \\ ${ }^{1}$ Cardiology Institute and Clinic, Poznan University of Medical Sciences, Poznan, Poland \\ ${ }^{2}$ Hypertensiology, Angiology and Internal Medicine Institute, Poznan University of Medical Sciences, Poznan, Poland \\ ${ }^{3}$ Erich \& Hanna Klessmann-Institute, Heart \& Diabetes Center NRW, Bad Oeynhausen, Germany \\ ${ }^{4}$ Department of Thoracic and Cardiovascular Surgery, Heart and Diabetes Center NRW Ruhr-University of Bochum, \\ Bad Oeynhausen, Germany
}

Kardiochirurgia i Torakochirurgia Polska 2018; 15 (4): 246-253

\begin{abstract}
Apical hypertrophic cardiomyopathy (AHCM) is a rare form of hypertrophic cardiomyopathy, occasionally resulting in severe complications. The paper covers the etiology and pathogenesis of AHCM, different imaging methods and characteristic appearance of the disease in each of them. Echocardiography and cardiovascular magnetic resonance imaging (CMR) are known to be the most valuable imaging methods. Moreover, this review presents medical and surgical treatment, as well as the clinical course and prognosis. Despite possible morbid events the overall cardiovascular mortality rate of AHCM patients is low, and the prognosis is relatively optimistic.
\end{abstract}

Key words: apical hypertrophic cardiomyopathy, sudden cardiac death, echocardiography, magnetic resonance imaging.

\section{Introduction}

Apical hypertrophic cardiomyopathy $(\mathrm{AHCM})$ is a rare medical condition, first introduced by Sakamoto et al. in 1976 [1], who described a cardiac disorder manifested by negative T-waves on electrocardiography, which was associated with apical hypertrophy of the left ventricle. According to the latest ESC guidelines hypertrophic cardiomyopathy (HCM) is defined by "the presence of increased left ventricular (LV) wall thickness that is not solely explained by abnormal loading conditions" [2]. Current guidelines do not classify AHCM as a separate form of HCM, recognizing it as an atypical form of HCM along with mid-ventricular obstruction. The AHCM represent predominant non-obstructive hypertrophy of the apex of the left ventricle appearing on echocardiography or angiography as an "ace-of-spades" pattern of the left ventricular cavity [1, 3, 4]. According to the extent of hypertrophy different types of AHCM can be

\section{Streszczenie}

Kardiomiopatia koniuszkowa (AHCM) jest rzadką postacią kardiomiopatii przerostowej, która w niektórych przypadkach powoduje poważne komplikacje. Autorzy przedstawiają etiologię i patogenezę AHCM oraz różne techniki obrazowania pozwalające na ustalenie rozpoznania. Echokardiografia i magnetyczny rezonans jądrowy są najlepszymi metodami diagnostycznymi. Ponadto autorzy omawiają aktualne metody leczenia farmakologicznego i chirurgicznego, a także przebieg kliniczny i rokowanie. Pomimo występowania poważnych powikłań śmiertelność pacjentów z AHCM jest stosunkowo mała, a przebieg łagodny.

Słowa kluczowe: kardiomiopatia przerostowa koniuszkowa, nagła śmierć sercowa, echokardiografia, magnetyczny rezonans jądrowy.

recognized: the "pure apical" form, where hypertrophy is localized in the apex distal to the papillary muscles, and the "distal dominant" form, where hypertrophy is present also proximal to the papillary muscle without involving basal segments of the septum. Kubo et al. observed different survival depending on type of hypertrophy [5].

\section{Epidemiology and etiology}

Hypertrophic cardiomyopathy is estimated to affect 1 out of 500 people. The AHCM has different prevalence in cohorts of patients with HCM. It is especially high in Japan and Asian countries. According to Kitaoka et al. prevalence in the Japanese population was $15 \%$ as compared to only $3 \%$ of a United States cohort [6]. Most patients with AHCM are male (74.4\%). The average age in the European cohort at presentation was $41.4 \pm 14$. 5 years, whereas age at diagnosis was $46.1 \pm 15.1$ years because of non-specific

Address for correspondence: Jerzy Paluszkiewicz, Cardiology Institute and Clinic, Poznan University of Medical Sciences, $1 / 2$ Długa St, 61-848 Poznan, Poland, e-mail: jpalusz@gmail.com

Received: 2.12.2018, accepted: 2.12.2018. 
complaints that make the diagnosis difficult [7]. Among patients in the Chinese population patients with the "distal dominant" form of AHCM were significantly older as compared to the "pure apical" form [8].

The HCM is inherited in most cases in an autosomal dominant pattern, associated with over 1,500 known mutations in at least 15 genes encoding proteins of the sarcomere. Mutations in the genes encoding $\beta$-myosin heavy chain (MYH7) and myosin-binding protein C3 (MYBPC3) were found to be the most frequent cause of HCM, differing in sources from $50 \%$ to $70 \%[9,10]$. Other less frequent mutations known to cause HCM are found in genes encoding for troponin I (TNNI3), troponin T (TNNT2), and $\alpha$-tropomyosin (TPM1) [9].

The AHCM has been recognized for its familial incidence; therefore a significant role of genetics for the pathogenesis of this disease has been suggested [10]. According to the study of Arad et al. only a limited number of sarcomere gene defects consistently result in apical hypertrophic cardiomyopathy. For example, a cardiac actin mutation (ACTC p.Glu101Lys) was found in all examined patients $(n=16)$ with AHCM [11]. Mogensen et al. and Olson et al. suggested that mutations on the myosin-exposed binding domain of cardiac actin possibly disrupt electrostatic interactions, weakening sarcomeric force generation, which results in the myocardial hypertrophic response $[12,13]$.

\section{Pathophysiology}

Thickening of the LV walls and especially of the apex results in decreased diastolic volume of the LV, consequently leading to decrease of cardiac output. This leads to worsening of exercise capacity and dyspnea. Left ventricular hypertrophy leads to myocardial ischemia along with formation of interstitial fibrosis, both responsible for increased myocardial stiffness and fibrosis. Mentioned changes in the LV result in diastolic dysfunction besides increased LV filling pressure. Change in LV filling pressure may lead to dilatation of the left atrium (LA), which increases the risk of atrial fibrillation (AF) episodes. Nevertheless, increased apical walls thickness can lead to mid-ventricular pressure gradient creation, which may result in formation of, characteristic for AHCM, apical aneurysm. The pressure created in the aneurysm can easily exceed $200 \mathrm{~mm} \mathrm{Hg}$. Such wall structure lesions are believed to be the reason for patients' chest pain complaints. In some cases, the pressure gradient between the aneurysm cavity and the rest of the ventricle persist during diastole, leading to reverse blood flow. Due to both AF and aneurysm formation AHCM not infrequently results in embolic evens (e.g. stroke).

\section{Clinical presentation}

The AHCM does not have any pathognomonic clinical symptoms. The main complaints of the patients are unspecific, leading to late diagnosis. The most common are atypical chest pain, dyspnoea, exercise intolerance, palpitations, atrial fibrillation as well as presyncope or syncope. In a series of 193 patients with AHCM dyspnea on exertion was reported by $38 \%$ of patients, angina by $8 \%$, syncope by $11 \%$ and signs of heart failure by $6 \%$ of patients. A history of hypertension was present in almost $30 \%$ of patients but interestingly was more frequent in women, up to $40 \%$. A history of HCM or sudden cardiac death (SCD) in family members was reported in general in $26 \%$ of patients, and less often in patients with the "pure apical" form [8]. Atrial fibrillation was present or reported by $22 \%$ of patients at presentation [14]. Occasionally morbid events such as sudden cardiac death, stroke, or myocardial infarction are the first manifestations of AHCM [7, 15]. Also congestive heart failure can be a first symptom of AHCM.

\section{Diagnosis}

\section{Electrocardiography}

Typical electrocardiographic pattern for AHCM are symmetrical deep negative T waves ( $\geq 1 \mathrm{mV}$ ) in precordial leads associated with high QRS voltage [16]. Depth of T waves varies among patients, $T$ wave inversions in precordial leads are found in $93 \%$ of cases, but "giant" $T$ waves $(\geq 1 \mathrm{mV})$ are found only in $47 \%$ of all patients with AHCM. Furthermore, $65 \%$ of patients present left ventricular hypertrophy (LVH) signs in electrocardiographic (ECG) examination [7]. Depth of $T$ waves may vary in a course of the disease. Negative $T$ waves in ECG are found less frequently in patients outside Japan. In the study of Kitaoka et al., giant T waves were present in $26 \%$ of patients with $\mathrm{HCM}$ as compared to $2 \%$ of United States patients [6]. Moreover, the segmental form of left ventricular hypertrophy was more common (15\%) in Japanese patients, as compared to $3 \%$ in US patients [6, 17]. Another suggested examination is Holter ECG, which is crucial to determine the presence of ventricular ectopies, as well as the presence of ventricular couplets (VE), VE bigeminies or non-sustained ventricular tachycardia (NSVT), which is defined as 3 or more ventricular beats [18]. Incidents of ventricular arrhythmias were found to correlate with the presence of fibrosis as found on cardiac magnetic resonance.

\section{Echocardiography}

Echocardiography probably plays the most important role in diagnosis of AHCM. Because of unspecific clinical symptomatic the diagnosis is often made by coincidence during screening echocardiographic examination. Because of frequent difficulties to delineate the endocardium, 2D echocardiography may provide false negative results, as reported by Yan et al., who found that in $31.7 \%$ of cases echocardiography initially failed to diagnose AHCM found later in CMR. Therefore negative results of echocardiographic examination especially without echocardiographic contrast should be considered with caution [8].

Typical echocardiographic signs of AHCM on echocardiographic examination include increased thickness of the left ventricular wall in the apical region. The cut-off value is fixed at $15 \mathrm{~mm}$ as measured below the insertion of the papillary muscle, although in the case of typical clinical symptoms and apex morphology a lower threshold of wall thickness (13-15 mm) can also be used. The typical echo- 

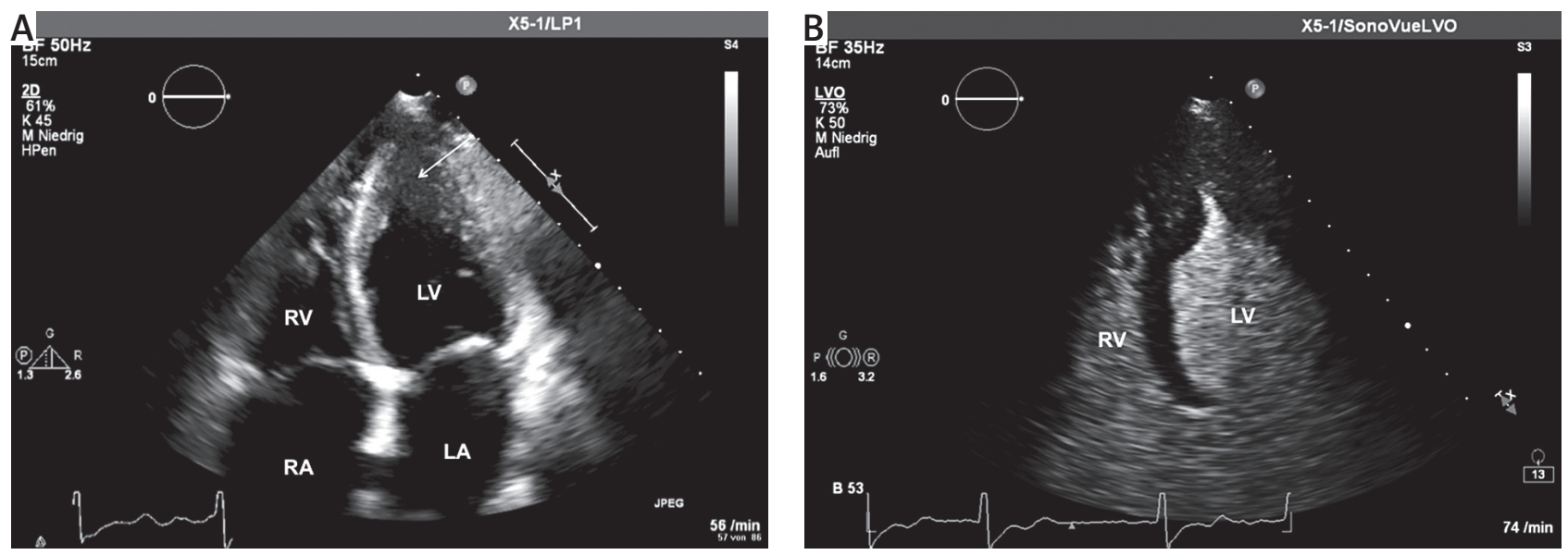

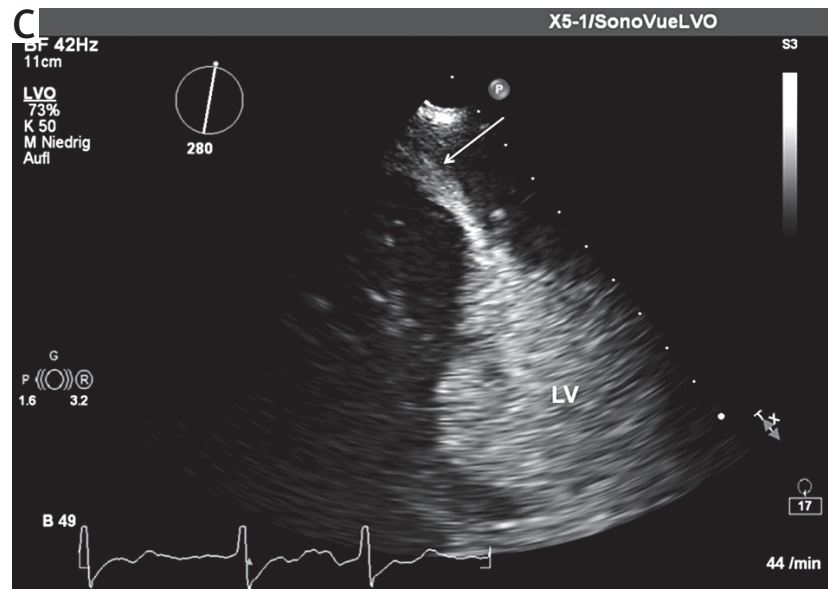

cardiographic shape of the left ventricle in the four-chamber view resembles the silhouette of an "ace of spades" (Figs. $1 \mathrm{~A}, \mathrm{~B}$ ). The administration of second generation echocardiographic contrast allows excellent visualization of morphology of the left ventricle and allows one to demonstrate the presence of apical aneurysm (Fig. 1 C). Assessment of the extent of left ventricular hypertrophy is a very important part of the examination and allows types of AHCM to be differentiated (see above). The Doppler assessment of possible interventricular gradients is of clinical importance and should be performed in every case. Detection of the diastolic gradient between the apex and the cavity of the left ventricle also plays an important prognostic role. It was found to increase thromboembolic risk, ventricular arrhythmias or perfusion abnormalities [19]. In most cases of AHCM global ejection fraction remains preserved, with significantly reduced end-diastolic volumes and signs of diastolic dysfunction. In the differential diagnosis, cardiac tumors, apical thrombus, non-compaction cardiomyopathy and coronary artery disease must be taken into account. Transesophageal echocardiography plays an important role during cardiac surgery and in detecting intracavitary thrombi.

\section{Cardiac magnetic resonance imaging}

Another examination useful in determining presence of $\mathrm{AHCM}$ is cardiovascular magnetic resonance (CMR), which
Fig. 1. A - Transthoracic echocardiography, four-chamber view. Patient with AHCM. Note the increased thickness of the apex of the left ventricle (arrow). B - Transthoracic echocardiography, fourchamber view. Contrast echocardiography (SonoVue). The same patient as in Figure $1 \mathrm{~A}$. Note the opacification of the left ventricle revealing typical silhouette of "ace of spades". C - Transthoracic echocardiography, four-chamber view. Patient with AHCM. Contrast echocardiography (SonoVue). Note the opacification of the left ventricle revealing the presence of apical aneurysm (arrow) LA - left atrium, LV - left ventricle, RA - right atrium, RV - right ventricle.

provides high-resolution images. The main advantage of CMR over echocardiographic examination is complete coverage of left ventricle morphology, including the apex. Therefore, CMR is used to determine the presence, site and extent of apical hypertrophy or aneurysm (Fig. 2 A). Characteristic findings for this type of HCM are obliteration in the region of the LV apex with a typical "ace-of-spades" silhouette of LV in the 2-chamber view, apex wall width >15 mm with basal/apex wall thickness ratio > 1.5 [20]. Cardiovascular magnetic resonance has also emerged as a powerful tool for the diagnosis of HCM, and has been recognized for its potential utility for improved risk stratification [21]. As myocardial fibrosis may underlie the arrhythmogenic substrate as well as promoting development of HF, recent studies have focused on late gadolinium enhancement (LGE) by CMR, a marker of fibrosis, as an independent risk factor for adverse outcomes (Fig. 2 B). A metaanalysis suggested that the presence of LGE (in up to $2 / 3$ of cases) is associated with cardiac death (odds ratio (OR) 2.9, $p<0.05$ ), HF $(\mathrm{OR}=5.7, p<0.01)$, and a trend for $\operatorname{SCD}(\mathrm{OR}=2.4, p=0.09)$ [22]. A retrospective study of 1293 patients demonstrated that LGE > 15\% of LV mass was associated with a 2-fold increase in SCD risk, suggesting that the amount of LGE rather than just its presence may be an important risk marker [23]. The LGE identifies replacement and interstitial fibrosis, but post-mortem analysis indicates that diffuse fibrosis is 

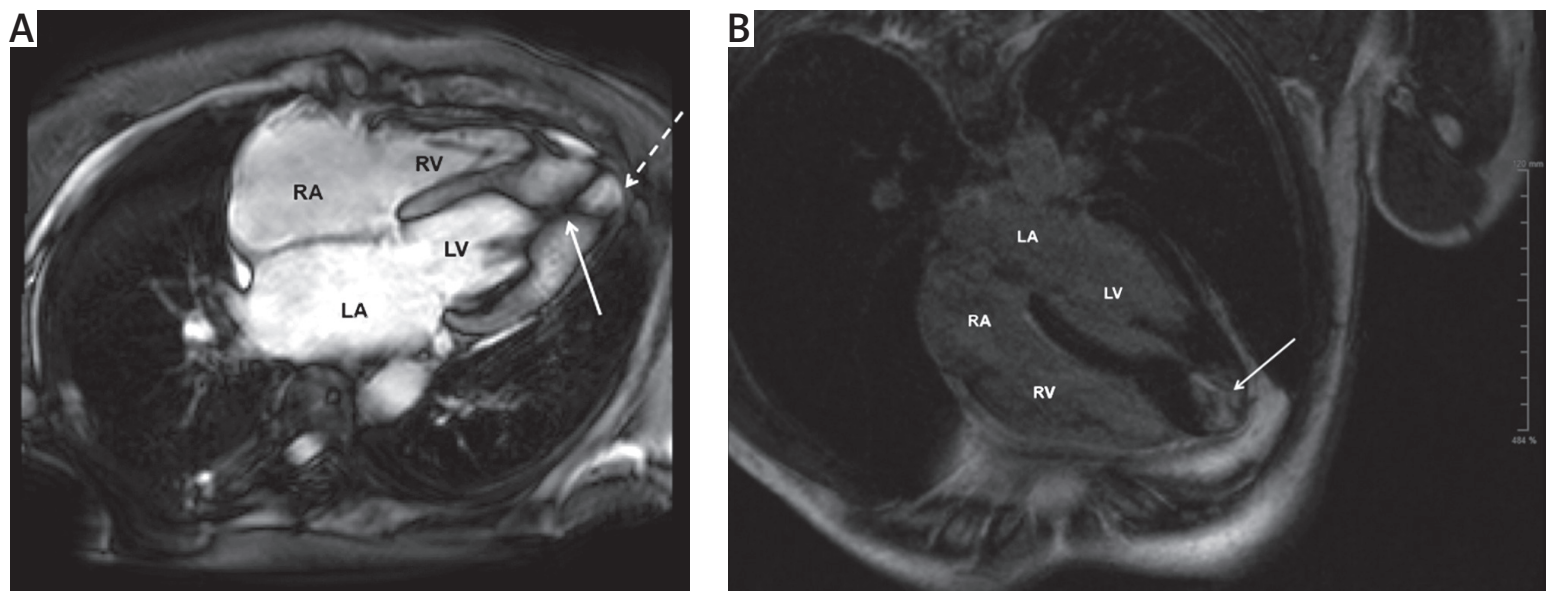

Fig. 2. A - Cardiac magnetic resonance, four-chamber view. Patient with AHCM. Note isolated apical hypertrophy (arrow) with apical aneurysm (dashed arrow). B - Cardiac magnetic resonance, four-chamber view. Patient with AHCM. Note apical fibrosis as revealed with gadolinium late enhancement (arrow)

LA - left atrium, LV - left ventricle, RA - right atrium, RV - right ventricle.

also present in other regions not identified by LGE. Recent advances in T1 mapping with CMR have enabled validation of diffuse interstitial fibrosis measurements in HCM and demonstration of increases, even in genotype (+), phenotype (-) patients [24]. Despite these advances, recent guidelines do not recommend the use of CMR for risk stratification [2, 25]. Moreover, CMR is important in management decisions of invasive therapies, especially by determining sites affected with HCM and localizing papillary muscles.

\section{Single photon emission computed tomography}

Single photon emission computed tomography (SPECT) plays a secondary role in diagnosing AHCM. It can detect local ischemia mostly in the left ventricular aneurysm, creating a typical picture of a "solar polar" map pattern [26].

\section{Angiography}

Cardiac catheterization, left ventricular and coronary angiography beside assessment of the coronary artery status can reveal the typical morphology of the left ventricle and presence of left ventricular aneurysm (Fig. 3). However, cardiac catheterization is not the main diagnostic tool used in patients with $\mathrm{AHCM}$.

\section{Treatment}

\section{Medical treatment}

The medical treatment of patients with apical form of HCM is similar to therapy used in the typical form of HCM. The use of a $\beta$-blocker or calcium channel blockers is recommended in patients with preserved ejection fraction in maximal tolerated doses. Because diastolic dysfunction is present in most patients with AHCM, prolonging diastole plays a beneficial role. In patients with depressed ejection fraction typical heart failure medication should be used. Patients with atrial fibrillation should receive anticoagulation therapy. Generally, the efficacy of medical treatment is

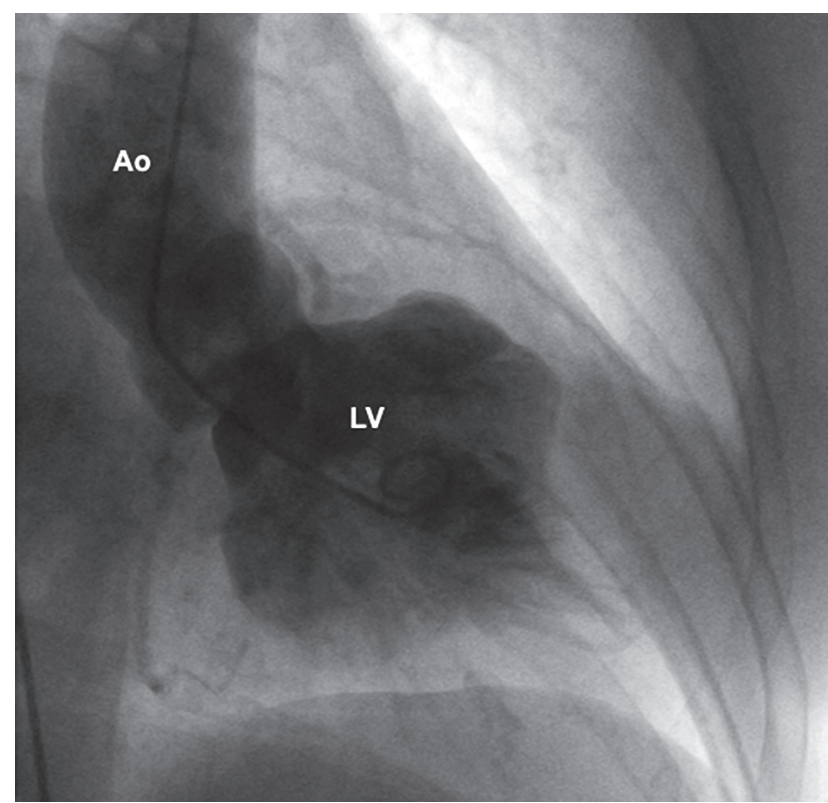

Fig. 3. Left ventricular angiogram in patient with known AHCM. Note the typical shape of the left ventricle with "ace of spades" silhouette

Ao - ascending aorta, LV - left ventricle.

not very high, and many patients are symptomatic in spite of pharmacological treatment. It concerns especially patients with apical aneurysm, severe diastolic dysfunction or severe reduced end-diastolic volume. In such cases a surgical treatment should be considered.

The risk of sudden cardiac death is lower in AHCM as compared to typical phenotype of HCM especially with left ventricular outflow tract obstruction. However, implantation of an implantable cardioverter defibrillator (ICD) could also be justified especially in patients with known risk factors such as a family history of sudden cardiac death, syncope, asymptomatic NSVT, an abnormal blood pressure response to exercise, as well as left ventricular wall thickness $>30 \mathrm{~mm}$ measured in the best available imaging method (Table I). 
Table I. Clinical profile of patients with the highest risk for sudden cardiac death who have an indication for ICD implantation. Modified from [4]

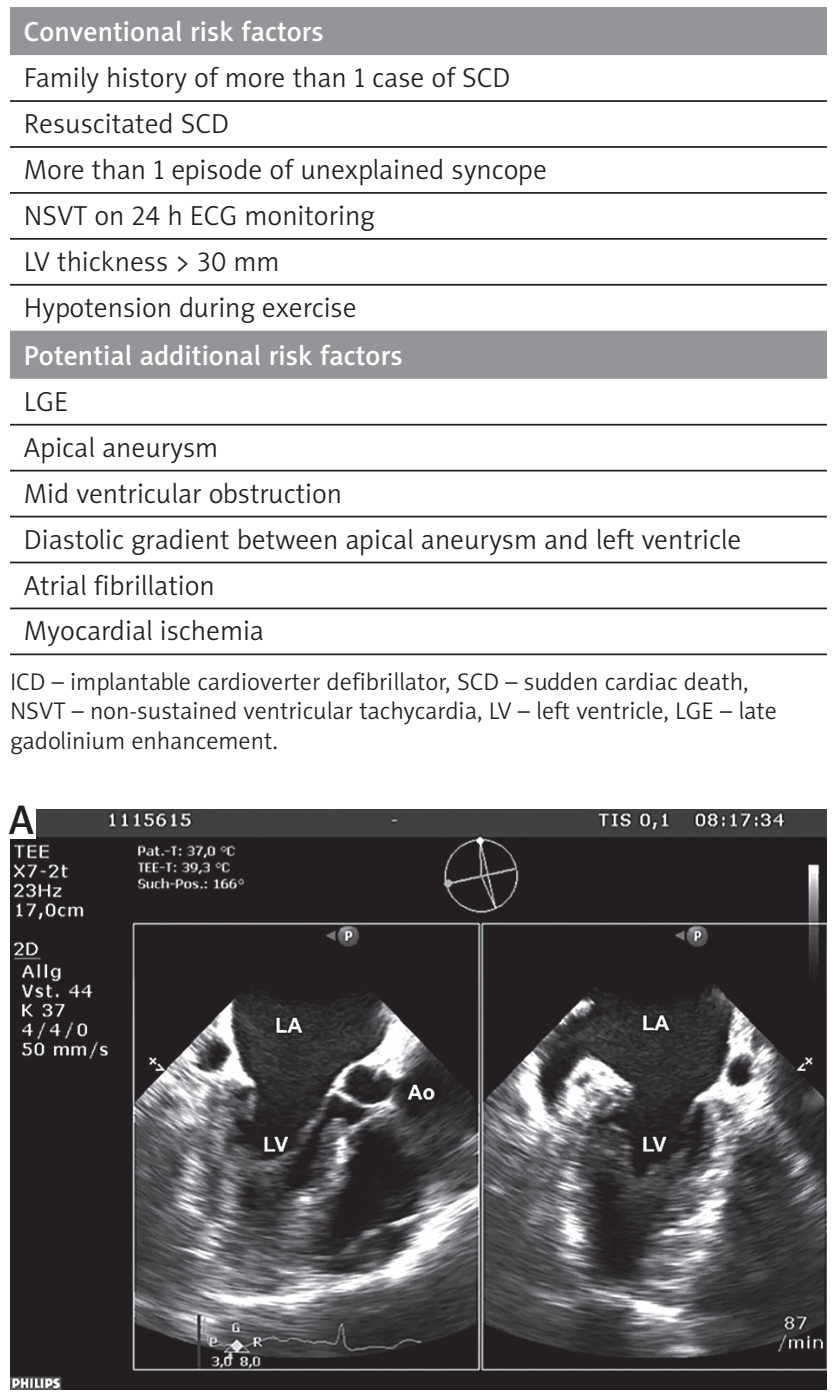

\section{Surgical treatment}

Surgical treatment for patients with typical phenotype of hypertrophic cardiomyopathy and obstruction of left ventricular outflow tract was first performed in 1959 [27]. Since that time surgical techniques have improved, and nowadays surgery is, together with alcohol ablation, the recommended method of treatment in patients refractory to medical treatment. For special forms of hypertrophic cardiomyopathy such as AHCM a unique procedure performed in a few centers has been described [28]. The patient with AHCM suffers due to diminished left ventricular volume caused by apex hypertrophy, which results in significant reduction of cardiac output. The aim of the surgical procedure is to increase the volume of the left ventricle through resection of hypertrophied apex muscle. Intraoperative transoesophageal echocardiography (TEE) plays a crucial role in planning the operation (Figs. 4 A, B). A transapical myectomy is performed by incising the apex of the left ventricle (Fig. 5 A). The excess tissue can be excised, paying attention to the papillary muscles. In some cases, with an especially prominent papillary muscle, they can also be trimmed or

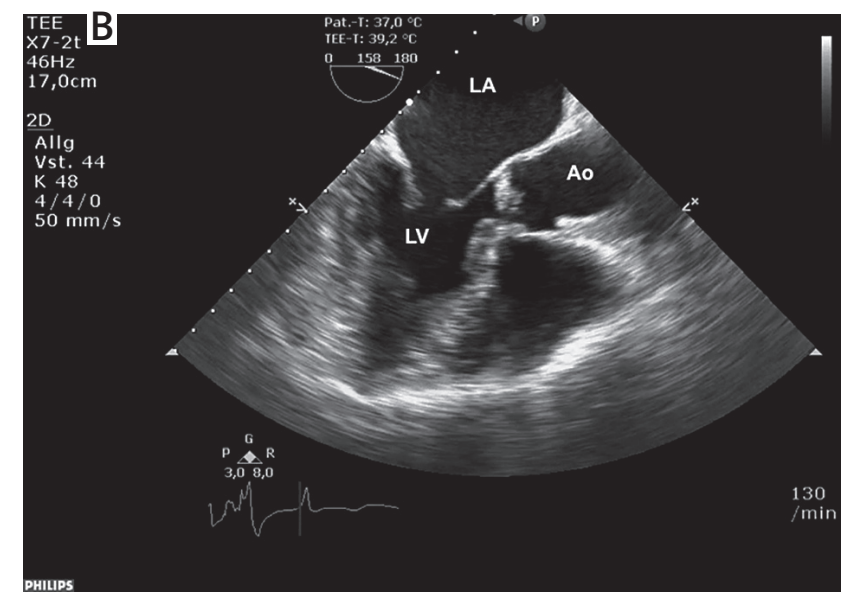

Fig. 4. A - Transoesophageal echocardiography, X-plane view. Patient with AHCM. Note the increased thickness of the apex and small end-diastolic volume of the left ventricle. B - Transoesophageal echocardiography, three-chamber view. The same patient as in Figure 4 A. Note the increased thickness of the apex and small end-diastolic volume of the left ventricle Ao - ascending aorta, LA - left atrium, LV - left ventricle.
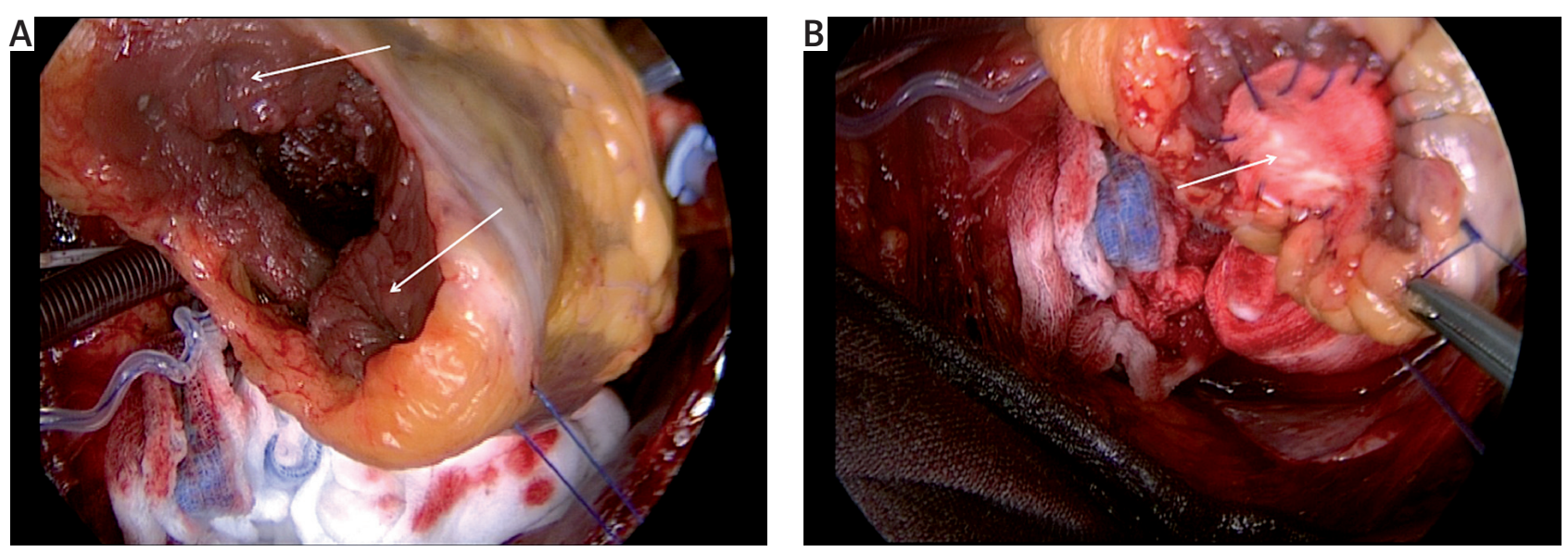

Fig. 5. A - Intraoperative picture of opened apex of the left ventricle. Note thickened apex of the left ventricle (arrow). B - Intraoperative picture after apical myectomy. Note presence of Teflon patch (arrow) closing apex of the left ventricle 

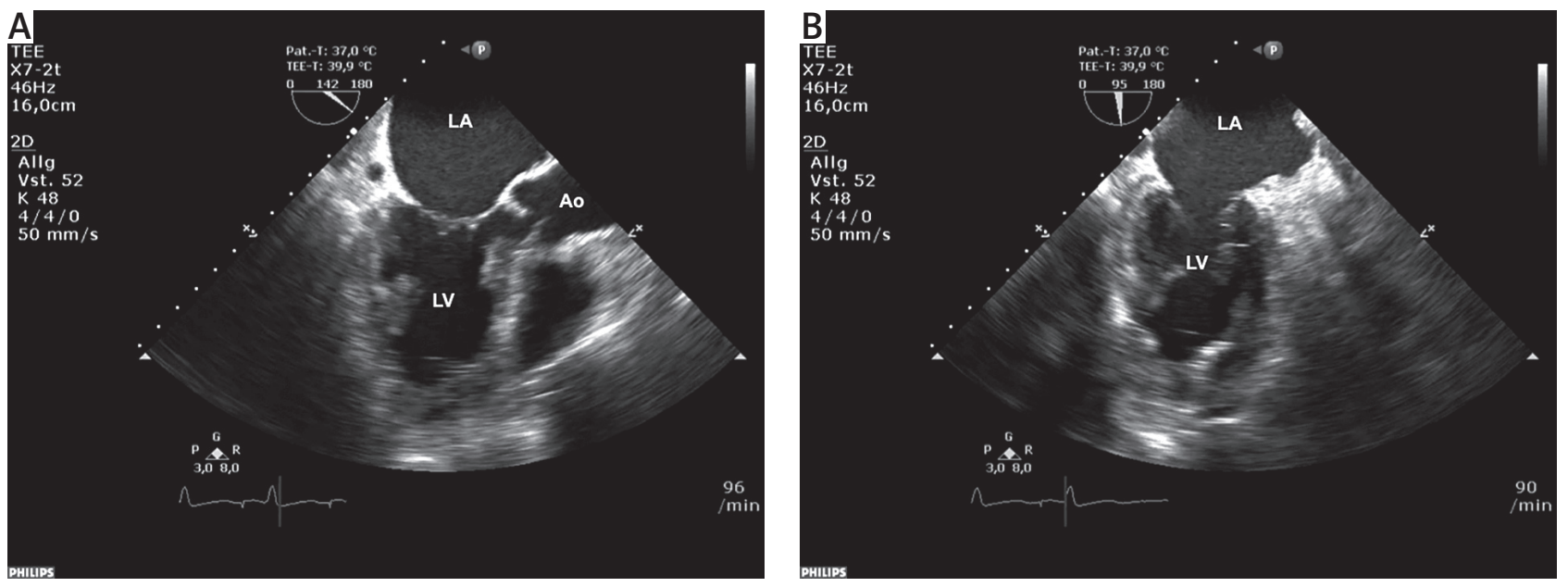

Fig. 6. A - Transoesophageal echocardiography, three-chamber view. The same patient as in Figures 4 A, B after myectomy. Note the increased end-diastolic volume of the left ventricle. B - Transoesophageal echocardiography, two-chamber view. The same patient as in Figures 4 A, B after myectomy. Note the increased end-diastolic volume of the left ventricle Ao - ascending aorta, LA - left atrium, LV - left ventricle.

exceptionally removed with implantation of a mitral valve prosthesis. The results are immediately proved by intraoperative TEE (Figs. 6 A, B). The second clinical issue concerns apical aneurysms, which are a possible source not only of thromboembolic material but also of ventricular arrhythmias. During myectomy excision of the existing aneurysm should be performed. The ventriculotomy is closed using a Teflon patch and linear stitches (Fig. 5 B). The short- and long-term results of apical myectomy are very good; a significant increase of end-diastolic volume can be observed (Figs. 7 A, B). In experienced centres operative mortality is low and do not exceed $1 \%$. During the 10 years follow up of 44 consecutive patients no thromboembolic complications were noted after surgery [29]. Also decreased incidence of arrhythmias was reported after surgery [30].

\section{Clinical course and prognosis}

The AHCM as compared with other forms of HCM has a favorable long-term prognosis. The over 15 years followup of a North American cohort of 105 patients with AHCM showed low cardiovascular mortality of $1.9 \%$. The incidence of morbid events was $30 \%$ with atrial fibrillation and myocardial infarction being the most frequent [7]. Klarich et al. observed a white Minnesota cohort of 193 patients for more than 20 years and found worse 20 -year survival in patients with AHCM versus expected for a normal population (47\% vs. $60 \%$ ). Also, SCD resuscitated cardiac arrest, and/or defibrillator discharge was observed in $6 \%$ of patients during followup. Interestingly, female gender was an independent risk factor of death [14]. In the observational study of 208 Chinese patients, only age $>60$ years, left atrial diameter $>36 \mathrm{~mm}$ and
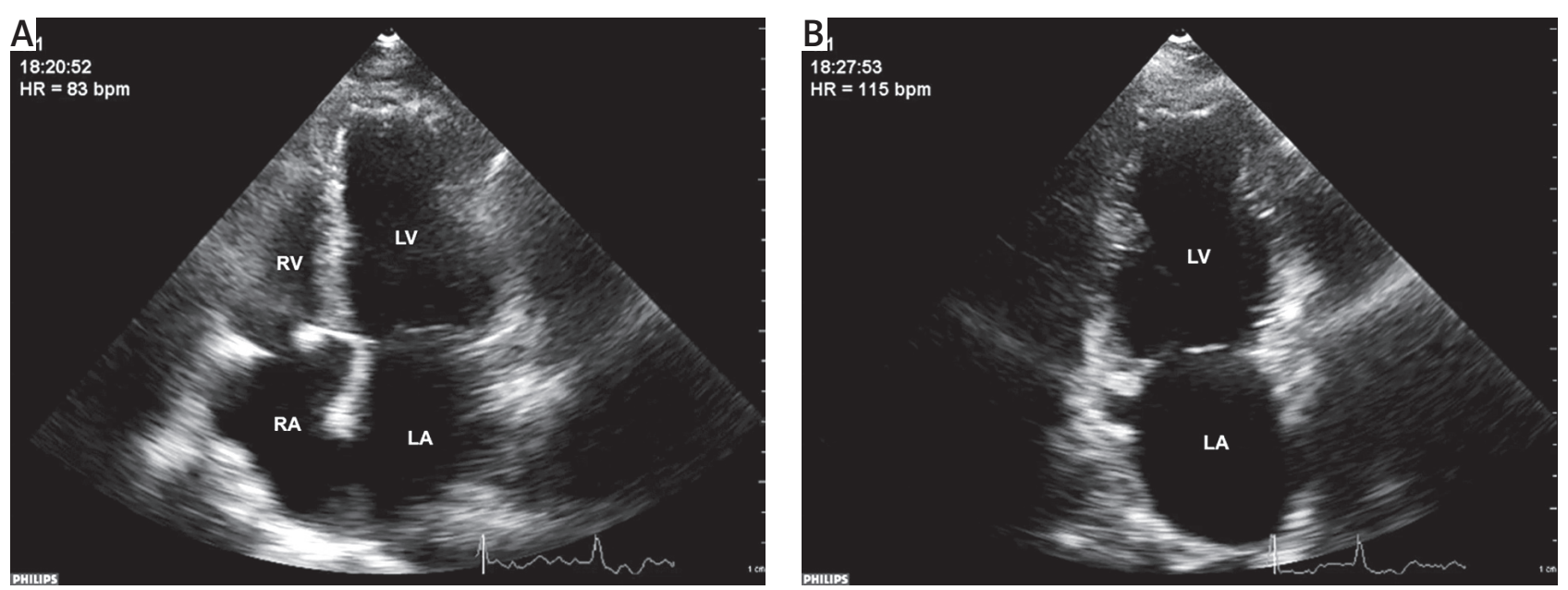

Fig. 7. A - Transthoracic echocardiography, four-chamber view. The same patient as in Figures 4 A, B 12 months after myectomy. Note the increased end-diastolic volume of the left ventricle. B - Transthoracic echocardiography, two-chamber view. The same patient as in Figures 4 A, B 12 months after myectomy. Note the increased end-diastolic volume of the left ventricle $L A$ - left atrium, LV - left ventricle, RA - right atrium, RV - right ventricle. 
NYHA class III were independently associated with increased risk of death. Female gender was not identified as a risk factor [8]. A coexisting coronary artery disease was identified as a strong negative predictor of survival in patients with AHCM [31]. The distribution of hypertrophy was found to influence survival; the "distal dominant" form and more severe hypertrophy were associated with worse prognosis [5]. Also, patients with apical aneurysm especially with diastolic gradient are more exposed to thromboembolic events. Patient with severe apical hypertrophy, with diminished left ventricular end diastolic volume or apical aneurysm can benefit from surgical treatment and should be referred for surgery. Summing up, the overall cardiovascular mortality rate of AHCM patients is low, and the prognosis is relatively optimistic.

\section{Conclusions}

Although apical hypertrophic cardiomyopathy is a rare disease, patients with non-specific cardiac complaints, such as chest pain, low exercise toleration or syncope events, should be examined for presence of AHCM, especially when the family history is burdened with SCD or HCM. Moreover, first-degree relatives of patients with AHCM should undergo brief cardiologic examination. ECG examination does not give a specific clinical image and should not be used to determine AHCM; therefore echocardiographic, or preferably CMR examination, should be performed to confirm the diagnosis. Surgical treatment can be performed in a selected group of patients with good short- and long-term results.

\section{Disclosure}

The authors report no conflict of interest.

\section{References}

1. Sakamoto T, Tei C, Murayama M, Ichiyasu H, Hada Y. Giant T wave inversion as a manifestation of asymmetrical apical hypertrophy (AAH) of the left ventricle. Echocardiographic and ultrasono-cardiotomographic study. Jpn Heart J 1976; 17: 611-629.

2. Authors/Task FM, Elliott PM, Anastasakis A, Borger MA, Borggrefe M, Cecchi F, Charron P, Hagege AA, Lafont A, Limongelli G, Mahrholdt H, McKenna WJ, Mogensen J, Nihoyannopoulos P, Nistri S, Pieper PG, Pieske B, Rapezzi C, Rutten FH, Tillmanns C, Watkins H. 2014 ESC Guidelines on diagnosis and management of hypertrophic cardiomyopathy: the Task Force for the Diagnosis and Management of Hypertrophic Cardiomyopathy of the European Society of Cardiology (ESC). Eur Heart J 2014; 35: 2733-2779.

3. Yamaguchi H, Ishimura T, Nishiyama S, Nagasaki F, Nakanishi S, Takatsu F, Nishijo T, Umeda T, Machii K. Hypertrophic nonobstructive cardiomyopathy with giant negative $T$ waves (apical hypertrophy): ventriculographic and echocardiographic features in 30 patients. Am J Cardiol 1979; 44: 401-412.

4. Jan MF, Todaro MC, Oreto L, Tajik AJ. Apical hypertrophic cardiomyopathy: present status. Int J Cardiol 2016; 222: 745-759.

5. Kubo T, Kitaoka H, Okawa M, Hirota T, Hoshikawa E, Hayato K, Yamasaki N, Matsumura Y, Yabe T, Nishinaga M, Takata J, Doi YL. Clinical profiles of hypertrophic cardiomyopathy with apical phenotype: comparison of pureapical form and distal-dominant form. Circ J 2009; 73: 2330-2336.

6. Kitaoka H, Doi Y, Casey SA, Hitomi N, Furuno T, Maron BJ. Comparison of prevalence of apical hypertrophic cardiomyopathy in Japan and the United States. Am J Cardiol 2003; 92: 1183-1186.

7. Eriksson MJ, Sonnenberg B, Woo A, Rakowski P, Parker TG, Wigle ED, Rakowski H. Long-term outcome in patients with apical hypertrophic cardiomyopathy. J Am Coll Cardiol 2002; 39: 638-645.
8. Yan L, Wang Z, Xu Z, Li Y, Tao Y, Fan C. Two hundred eight patients with apical hypertrophic cardiomyopathy in China: clinical feature, prognosis, and comparison of pure and mixed forms. Clin Cardiol 2012; 35: 101-106.

9. Mirabbasi SA, Khalighi K, Mukkamala S, Kodali A. A rare case of apical hypertrophic cardiomyopathy (AHCM). J Community Hosp Intern Med Perspect 2017; 7: 122-125.

10. Akhtar M, Elliott P. The genetics of hypertrophic cardiomyopathy. Glob Cardiol Sci Pract 2018; 2018: 36.

11. Arad M, Penas-Lado M, Monserrat L, Maron BJ, Sherrid M, Ho CY, Barr S, Karim A, Olson TM, Kamisago M, Seidman JG, Seidman CE. Gene mutations in apical hypertrophic cardiomyopathy. Circulation 2005; 112: 2805-2811.

12. Mogensen J, Perrot A, Andersen PS, Havndrup O, Klausen IC, Christiansen M, Bross P, Egeblad H, Bundgaard H, Osterziel KJ, Haltern G, Lapp H, Reinecke P, Gregersen N, Børglum AD. Clinical and genetic characteristics of alpha cardiac actin gene mutations in hypertrophic cardiomyopathy. J Med Genet 2004; 41: e10.

13. Olson TM, Doan TP, Kishimoto NY, Whitby FG, Ackerman MJ, Fananapazir L. Inherited and de novo mutations in the cardiac actin gene cause hypertrophic cardiomyopathy. J Mol Cell Cardiol 2000; 32: 1687-1694.

14. Klarich KW, Attenhofer Jost CH, Binder J, Connolly HM, Scott CG, Freeman WK, Ackerman MJ, Nishimura RA, Tajik AJ, Ommen SR. Risk of death in long-term follow-up of patients with apical hypertrophic cardiomyopathy. Am J Cardiol 2013; 111: 1784-1791.

15. Yusuf SW, Bathina JD, Banchs J, Mouhayar EN, Daher IN. Apical hypertrophic cardiomyopathy. World J Cardiol 2011; 3: 256-259.

16. Choi EY, Rim SJ, Ha JW, Kim YJ, Lee SC, Kang DH, Park SW, Song JK, Sohn DW, Chung N. Phenotypic spectrum and clinical characteristics of apical hypertrophic cardiomyopathy: multicenter echo-Doppler study. Cardiology 2008; 110: 53-61.

17. Maron BJ. The giant negative T wave revisited in hypertrophic cardiomyopathy (editorial). J Am Coll Cardiol 1990; 15: 972-973.

18. Rubinshtein R, Glockner JF, Ommen SR, Araoz PA, Ackerman MJ, Sorajja P, Bos JM, Tajik AJ, Valeti US, Nishimura RA, Gersh BJ. Characteristics and clinical significance of late gadolinium enhancement by contrast-enhanced magnetic resonance imaging in patients with hypertrophic cardiomyopathy. Circ Heart Fail 2010; 3: 51-58.

19. Nakamura T, Matsubara K, Furukawa K, Azuma A, Sugihara H, Katsume H, Nakagawa M. Diastolic paradoxic jet flow in patients with hypertrophic cardiomyopathy: evidence of concealed apical asynergy with cavity obliteration. J Am Coll Cardiol 1992; 19: 516-524.

20. Brenes JC, Doltra A, Prat S. Cardiac magnetic resonance imaging in the evaluation of patients with hypertrophic cardiomyopathy. Glob Cardiol Sci Pract 2018; 2018: 22.

21. Maron MS. Clinical utility of cardiovascular magnetic resonance in hypertrophic cardiomyopathy. J Cardiovasc Magn Reson 2012; 14: 13.

22. Green JJ, Berger JS, Kramer CM, Salerno M. Prognostic value of late gadolinium enhancement in clinical outcomes for hypertrophic cardiomyopathy. JACC Cardiovasc Imaging 2012; 5: 370-377.

23. Chan RH, Maron BJ, Olivotto I, Pencina MJ, Assenza GE, Haas T, Lesser JR, Gruner C, Crean AM, Rakowski H, Udelson JE, Rowin E, Lombardi M, Cecchi F, Tomberli B, Spirito P, Formisano F, Biagini E, Rapezzi C, De Cecco CN, Autore C, Cook EF, Hong SN, Gibson CM, Manning WJ, Appelbaum E, Maron MS. Prognostic value of quantitative contrast-enhanced cardiovascular magnetic resonance for the evaluation of sudden death risk in patients with hypertrophic cardiomyopathy. Circulation 2014; 130: 484-495.

24. Flett AS, Hayward MP, Ashworth MT, Hansen MS, Taylor AM, Elliott PM, MCGregor C, Moon JC. Equilibrium contrast cardiovascular magnetic resonance for the measurement of diffuse myocardial fibrosis: preliminary validation in humans. Circulation 2010; 122: 138-144.

25. Gersh BJ, Maron BJ, Bonow RO, Dearani JA, Fifer MA, Link MS, Naidu SS, Nishimura RA, Ommen SR, Rakowski H, Seidman CE, Towbin JA, Udelson JE, Yancy CW, American COCFHATFOPG, American AFTS, American SOE, American SONC, Heart FSOA, Heart RS, Society FCAAI, Society OTS. 2011 ACCF/ AHA guideline for the diagnosis and treatment of hypertrophic cardiomyopathy: executive summary: a report of the American College of Cardiology Foundation/American Heart Association Task Force on Practice Guidelines. Circulation 2011; 124: 2761-2796.

26. Cianciulli TF, Saccheri MC, Masoli OH, Redruello MF, Lax JA, Morita LA, Gagliardi JA, Dorelle AN, Prezioso HA, Vidal LA. Myocardial perfusion SPECT in the diagnosis of apical hypertrophic cardiomyopathy. J Nucl Cardiol 2009; 16: 391-395. 
27. Goodwin JF, Hollman A, Cleland WP, Teare D. Obstructive cardiomyopathy simulating aortic stenosis. Br Heart J 1960; 22: 403-414.

28. Nguyen A, Schaff HV. Surgical myectomy: subaortic, midventricular, and apical. Cardiol Clin 2019; 37: 95-104.

29. Nguyen A, Schaff HV, Nishimura RA, Dearani JA, Ommen SR. Early outcomes of repair of left ventricular apical aneurysms in patients with hypertrophic cardiomyopathy. Circulation 2017; 136: 1979-1981.
30. Nguyen A, Schaff HV. Electrical storms in patients with apical aneurysms and hypertrophic cardiomyopathy with midventricular obstruction: a case series. J Thorac Cardiovasc Surg 2017; 154: e101-e103.

31. Shin DG, Son JW, Park JY, Choi JW, Ryu SK. Impact of coronary artery anatomy on clinical course and prognosis in apical hypertrophic cardiomyopathy: analysis of coronary angiography and computed tomography. Korean Circ J 2015; 45: 38-43. 